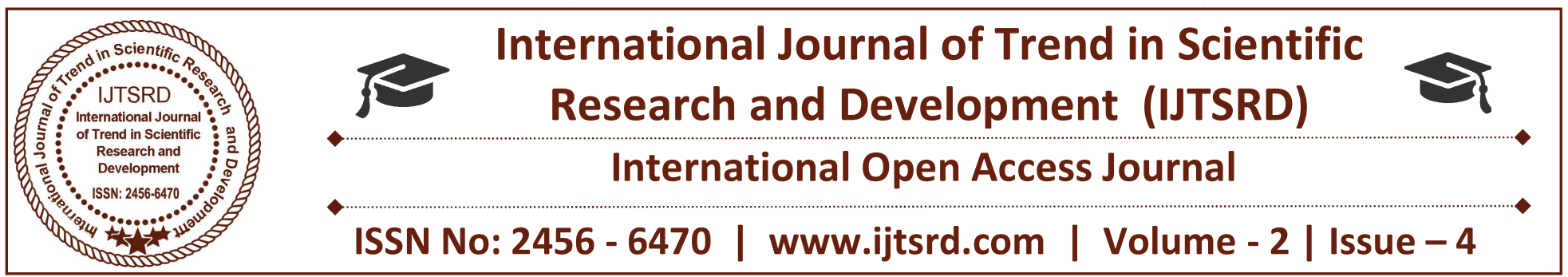

\title{
Global Leadership: A Privation for Global Corporate
}

\author{
Prof. Dr. Satya Subrahmanyam \\ Head and Managing Partner, Vignan Institute \\ of Technology and Management, Berhampur, Odisha, India
}

\section{INTRODUCTION}

MNEs, small and medium-sized enterprises (SMEs) and born global are all representatives of a changing business environment, by their participation in international business. Where international business is a term used for describing businesses ability to move factors of production across countries in order to gain a competitive edge. International business opportunities illustrate the choices a business face today (Czinkota et al., 2009).

\section{Background to the Problem}

Globalisation has increased the proximity of national markets, where multinational enterprises have a clear dominance in everyday life of the consumer. Globalisation has increased the consumer options as well as possibilities and competition businesses experience. Businesses source for competitive advantage is no longer solely dependent on knowledge about the national market.

Globalisation has developed a change in a way to conduct business. The need to create synergies between different cultural impulses and have a market outlook with a global horizon creates several new challenges for the corporate both in terms of strategy development and corporate culture. The need to create synergies across markets needs leadership orientation different from operating in a national market.

\section{Statement of the Problem}

It is still a corporate choice to go global where a global business is created when the business decides to expand its activities and starts trading using global business opportunities (Leung et al., 2005). However, it has become significantly difficult for businesses to seek refuge in national markets (Etemed, 2004). By joining in the global market, the local corporate needs to reshape and create a global strategy reflecting what the corporate wants to achieve engaging in global business (Leung et al., 2005). The ability to create synergies between the home country corporate and host country is crucial for successful globalisation. Leung et al., (2005) focuses on an international subsidiary start-up, where the corporate need to have grounded corporate values, attitudes and believes that can be transferred to the local subsidiary. In fact, the entire corporate will be influenced by the internationalization decision. The business strategy and corporate values will be altered by the interaction between different nationalities.

Globalisation has given rise to new means of internationalization. Traditional internationalization theories have described incremental steps towards international markets, exploring markets with low psychic distance (Johnson \& Vahlne, 1977). Such models of internationalization are challenged by internationalization that happens soon after conception. Globalisation has decreased the perceived psychic distance e.g. the factors that make it difficult to understand environments (Johnson \& Vahlne, 2009). It has also created a larger playing field for businesses, both encouraging internationalization and making it practically impossible to operate without international influence. 


\section{Purpose of the Study}

With globalization global leadership is a necessity, as global corporate need to communicate their strategic intent across national borders and create synergetic effects across both cultural and strategic diversity. Traditionally, the development of global leaders has focused on the role expatriation plays in international subsidiaries. Where expatriates are used as a knowledge agent from the parent-subsidiary to the foreign subsidiary e.g. agents for transferring knowledge between home and host country (Hocking, Brown \& Harzing, 2007). As international activities grow, there is a need for a leader that is able to work in multinational groups and be able to execute corporate global strategies and create common goals for performance achievement. The management is in charge of creating an encompassing strategy, but the leaders are responsible for leaning and influencing a diversity of cultures in terms of employees, customers, competitors and suppliers (Bowen \& Inkpen, 2009). Globalisation has changed leaders into a knowledge worker, a person with the ability to initiate global networking and creation of team activities (Soderberg \& Holden, 2002).

The literature on global leadership has focused on the need for successful global leaders in order to be able to survive in a global arena. Competencies and constructs defining global leadership and how global leaders are developed are common focuses. Another focus is the distinction between global and domestic leadership (Bird et al., 2010) which is generally described as the increased complexity of a leaders work, owing to the pressures and dynamics of global competition (Osland, 2008). Global leaders have been characterized as a leader that has an advanced ability to adapt to cultural specifics, such that becomes second to nature and subconscious (Zander et al., 2013). The global leader is responsible for disseminating the integrating the corporate global strategy as well as bridging an understanding between the team, subsidiary or department. The ability to interact in a diversified setting will be global leader's key strength.

\section{Review of Literature}

Globalisation opens up for new business opportunities. Businesses are able to expand and explore opportunities across countries, gaining new customers and competitors. Despite all the opportunities globalization creates, it also creates new challenges. A challenge for corporate in the global business environment is to create global leaders (Javidan \& House, 2001)

Traditional corporate leadership theories are concerned with influencing, motivating and assisting followers to desired levels of performance (Ahlstrom \& Bruton, 2010). What traditional corporate leadership theories do not grasp is the cultural aspects of leadership. How corporate leadership influenced by norms, believes and values of a society and hence needs to be adjusted from country to country. The approach to corporate leadership is affected by culture, providing different perceptions and characteristics to how a leader should act (Suutari, 2002).

To create an encompassing understanding of the global leadership, first the leadership is defined and a brief outline of the leadership theories discussed. Second, an attempt was made to define the global leadership. Third, the confusion between leadership and management that existed in the global leadership literature and the concern for the future development of the global leadership phenomenon is discussed. Fourth, global leadership literature identified several competencies necessary, such as global knowledge, leadership traits and cultural intelligence for successful leadership covered. Lastly, a look at the ways that proposed by literature for global leaders development was reviewed.

\section{Leadership}

Leadership is a dominant field of research within corporate and management research (Sanzher, Nardon \& Steers, 2011). The attempts to define corporate leadership are many (Yukl, 2010). A review of corporate leadership definitions (Yukl, 2010), identifies one commonality. The general process of intentionally influencing other people in order to guide, structure and facilitate activities and relationships in a group or organizations, depicts what corporate leadership constitutes of.

The different leadership theories developed can be divided into three categories: trait theory, contingency theory and behavioural theory (Ahlstrom \& Bruton, 2010), which are each classified with their own perspective on leadership development. The earliest attempt to theory development of leadership is trait theory. Trait theory posits that successful leaders will adopt a range of physical and personal attributes. Successful leaders should be able to adapt to new 
situations, be emotionally stable, trustworthy, selfconfident and energetic (Kuada, 2010). Trait theorists believe that people that posit such traits can be directly recruited into leadership positions, without any further training and adaption (Bolden et al., 2003).

Behavioural theories have a different approach to understanding corporate leadership. Where trait theory assumes that corporate leadership characteristics are determined by birth, behavioural theorists believe that corporate leadership traits can be learned. Behavioural theorists assume that it is possible to identify wanted leadership behaviour and create such behaviour through effective teaching (Ahlstrom \& Bruton, 2010).

Contingency or situational theory takes the contextual setting into consideration. Where trait theory assumes that a corporate leader most possesses a certain set of attributes, contingency theory assumes that there are so such thing as a universal approach to corporate leadership (Sanzhez-Runde, Nardon \& Steers, 2011). Different settings will call for different leadership styles (Ahlstrom \& Bruton, 2010). The advantage of contingency theories is that it is able to acknowledge that different cultural settings require different leadership styles.

Leaders today operate in a more and more global context and researchers have coined the term global leadership. Global leadership is a phenomenon that embraces the new challenges leaders face today. Leading people from different cultural, geographical, social and political contexts creates a new dimensionality to the general aspect of leadership (Sanchez-Runde, Nardon \& Steers, 2011; Terrell \& Rosenbusch, 2013). Hence, leaders in a global context have to accept an increasingly complex environment.

\section{Global Leadership Defined}

The phenomenon global leadership is a relatively new field of research and has received less attention than domestic leadership (Morrison, 2000). Global Leadership literature has had different approaches to understand, define and develop global leaders. The necessity of global leaders is an outcome of globalization and the increasing demand for global competitiveness. Global leadership has been discussed from a leadership (Sanchez-Runde, Nardon \& Steers, 2011), Strategic (Bucker \& Poutsma, 2009) and Intercultural Management perspective (Butler et al., 2012) or a combination of the three.

Global leadership definition brings in the aspect of influencing others, as leadership theories do, but emphasize on the ability to influence others based on cultural diversity. Constructs such as global business knowledge, business savvy, business expertise and vision are competencies related to many of explanations of global leadership. A global leader requires a more explicit knowledge about the markets the business operates in, in order to handle the balance of firm's strategic direction (Bucker \& Poutsma, 2009). The corporate global strategy and the need for global leaders are correlated. The larger global orientation, the more global leaders the corporate needs and vice versa (Morrison, 2000).

\section{Global Leaders Vs Global Managers}

As in leadership literature, the confusion concerning the distinction between global leaders and global managers exists. According to Bucker and Poutsma (2009), there is no consistency in the literature between /r management and leadership skills, knowledge and other personality factors. Osland et al., (2006) proclaims that one of global leadership literature's weakness is the failure to distinguish between global leadership and global management.

The distinction provided by Kotter (1990) is between management needs to cope with complexity and leadership needs to cope with change, which provides a set of different action points. Hence, distinguishing between leadership and management creates a separation between leaders' and managers' role. However, this distinction between management and leadership has not become prominent in global leadership literature.

The conceptualization of how culture affects global leadership competencies provided by Sanchez-Runde, Nardon and Steers (2011) mixes the two concepts. Kets de Vries and Florent-Treacy (2002) deliberately mix the concepts of leadership and management in their explanation of global leadership. The separation between leadership and management is concerned with the actions or set of activities the role constitutes of. The distinction between a leader and a manager and a global leader and global manager will base on this set of activities. A global leader creates a vision, influence and motivates people in order to achieve set goals, while a global manager is concerned with the global planning, resource management and 
operational control. Global leaders tend to an increasingly complex environment, rather than just national culture.

However, the separation between global managers and global leaders does not mean that, as with leaders and managers, the same person cannot posit both roles. Global leaders and global managers are roles that an individual have and there is no restriction on having both a global manager and global leader role at the same time. Both roles require an understanding of the diversity global operations provides but global leaders require the ability to bridge understanding between different people while global managers need a more technical insight in distributing resources correctly.

\section{Global Leadership Competencies}

The characterization of universal global leadership competencies is impossible. Global leadership styles are complex dependent and hence the ability to influence employees across a culturally complex environment will need to have a flexible orientation towards leadership styles and methods. Global leadership is based on the cultural context as well as the expectations towards leaders (Sanchez-Runde, Nardon \& Steers, 2011). Competencies are defined as knowledge, skills, abilities and behaviours that allow a person to perform his/her job (Caligiuri, 2006). Global leadership literature has focused on several such competencies, which are both dependent on traits, knowledge and cultural interaction. Construct such as global knowledge, e.g. business and corporate knowledge, self-awareness, inquisitiveness, integrity, emotional and cultural intelligence are commonly used describing global leadership.

\section{Global Knowledge}

A factor separating global leaders from domestic leaders is the need for extensive global knowledge. Global knowledge constitutes of business and corporate knowledge. Business knowledge is crucial for global leaders. To understand the business strategic direction, being able to understand markets and prepare for tomorrows leadership challenges (Rosen \& Digh, 2001). Business knowledge will aid in balancing the strategic direction of the business, in order to meet the global markets challenges. It will aid in the identification and pursuit of new market opportunities. Global leaders with good business knowledge will be able to understand political, sociocultural and financial contexts of foreign markets and have an interdisciplinary business understanding (Conner, 2000).

Global leaders not only need to understand the changes in business operations across cultural contexts, he/she must also understand how global operations affect the corporate environment. Hence, global leaders require corporate knowledge. The corporate context changes due to global spanning activities. The global leader will need to understand how cultural diversity affects the corporate, what resources the corporate possess and how to effectively organize and lead multicultural teams (Gregersen, Morrison \& Black, 1998).

\section{Global Leadership Traits}

Global leaders need to have a strong character in order to influence others unlike themselves (Conner, 2000), hence global leaders need to possess some specific traits. The focus on global leadership traits has been predominant in global leadership literature (Sutton, Zander \& Stamm, 2013) and there are large commonalities in the identified traits. Self-awareness, inquisitiveness, integrity and emotional intelligence are commonly used traits for explaining global leadership (Bird et al., 2010).

Self-awareness reflects a person understands his/her own emotions, strength and weaknesses, needs and drivers, sources of frustration ad reactions to problems (Jokinen, 2005). Global leaders with a deep selfawareness are able to understand how he/she should tackle new and complex situation and also know what abilities that need to be developed. Closely connected to self-awareness is the trait self-confidence. Global leaders must be self-aware in order seek out unfamiliar situations and challenge his/herself (Kets de Vries \& Florent-Treacy, 2002).

Inquisitiveness reflects a genuine curiosity towards the world. Displaying a willingness to pursue new things and be able to identify a meaning and avoid stereotyping (Bird et al., 2010). The drivers from exploring new settings and challenging his/her own comfort zone will enable the global leader to expand on his/her global knowledge (Gregersen et al., 1998). Inquisitiveness is an important trait for global leaders, due to the influence it has on the willingness and the motivation to explore new challenges. Without motivation and the wish to seek out unfamiliar settings, global leaders will not succeed (Jokinen, 2005). 
A third trait necessary for global leadership is the ability to show integrity. The need to have know-how in order to influence employees and create productive networks of people to produce desired outcomes (Conner, 2002), but to exert influence over others requires a consistency towards leadership. The ability for a global leader to show consistency in his/her actions can create a feeling of trust and commitment to his/her communicated visions (Gregersen et al., 1998). Integrity allows the leader to build trust and stability towards his/her leadership approach.

A global leader's emotional intelligence is the genuine ability to interact with others (Gregersen et al., 1998) also called empathy (Jokinen, 2005). Emotional intelligence is interlinked with self-awareness. One cannot be aware of and manage other people's emotion if not aware of one's own. According to Gregersen et al. (1998), there is a three-step process to display of high emotional intelligence - 1. A genuine concern for others, 2. Ability and effort to listen to others and 3. Ability and wish to understand different viewpoints.

The four traits identified here are all interconnected. The degree of self-awareness will influence a person's inquisitiveness, integrity and ability to show empathy. Inquisitiveness will influence knowledge creation and the attempt to seek new opportunities, having a positive influence on the other traits. Global leaders require a more curiosity seeking nature than domestic leaders, in order to cope with the changing business environment.

\section{Cultural Intelligence}

Another crucial aspect of global leadership is cultural diversity. The need to understand and negotiate meaning across a multicultural context requires an extensive cultural intelligence, as the stakeholders a global business and leaders must relate to having increased numerously $\mathrm{m}$ (Sutton, Zander \& Stamm, 2013) Nardon and Steers (2008) even go the extent to say it is unavoidable to work without international competition or business partners in today's business world.

Cultural intelligence is necessary in order to have an effect emotional intelligence, due to the need to understand the meaning behind emotions in a crosscultural setting (Alon \& Higgins, 2005). High emotional intelligence enables the global leaders to acknowledge differences, whereas high cultural intelligence will enable the global leaders to identify differences among people and groups (Earley \& Mosakowski, 2004).

Cultural intelligence will avoid making bad judgements, based on stereotyping and failure to understand cultural paradoxes. A higher cultural intelligence will increase the global leader's knowledge and ability to build a consistent leadership style and exert a concern for others. The global leaders need to learn 'cultural schemas' in order to work effectively in a cross-cultural setting (Osland \& Bird, 2000). However cultural intelligence is context dependent. No matter how well one learns about other cultures, the major test is the understanding of people's interactions. A person may act and create opinions based on his/her nationality or based on the specific role, e.g. job position, he/she has misinterpretations of a person's behaviour can lead to leadership failure (Earley \& Mosakowski, 2004).

Cultural is part of the individual, hence the individual's norms and values are a part of forming any group of people team, subsidiary and corporate. For global leaders to be effective they need to be able to make sense of the meanings created by people of various backgrounds. They need to be able to apply the emotional intelligence in cross-cultural settings, display integrity, be curious about the new contexts and be aware of his/her own abilities. It is important when entering in a new setting that the global leader not only possess the right leadership traits but that he/she also has extensive knowledge about the corporate culture he/she coming from and entering in to (Alon \& Higgins, 2005).

\section{Development of Global Leaders}

The issue of development of global leaders has been heavily discussed in global leadership literature. It is easier to find a proposal of how to develop a global leader than to find a clear definition of global leadership. Development of global leaders is broadly seen as a process of four factors - training, experience, personal competencies and ad hoc experiences (Terrell \& Rosenbusch, 2013).

Globalisation has changed the composition of the workforce and has created new corporate challenges. The need to maintain a competitive advantage in order to survive in a global context is prominent (Kiessling \& Harvey, 2005). The most important thing corporate have is its knowledge and competencies (Stroh \& Caligiuri, 1998). Globalisation has created new issues, such as expatriation, repatriation and a 
multicultural workforce both domestically and internationally, which businesses need to take into account (Kiessling \& Harvey, 2005), creating a need for global leaders.

Training can be used to provide 'cultural schemas' for the individual. The Global Leadership and Organisational Behaviour Effectiveness (GLOBE) study is one such approach towards providing the simplistic understanding of how culture affects behaviour across the globe. It explores the cultural values and practices in a wide variety of countries and to identify their impact on corporate practices and leadership attributes (House et al., 2002). Through identifying nine cultural dimensions - performance orientation, future orientation, assertiveness, uncertainty avoidance, power distance, collectivism, family collectivism, gender differentiation and human orientation - the GLOBE study aims to be a tool for global leaders to improve cultural understanding, the ability to make sophisticated stereotyping and exert necessary cultural sensitivity (Javidan \& House, 2001).

Experience is the common denominator for successful global leadership development. Gaining theoretical knowledge will not improve emotional and cultural intelligence and prepare the leader for cultural paradoxes. Cultural development is an on-going, never-ending process and only through interactions can individuals be able to fully understand that specific corporate or group culture. As group identify might differ from national culture (Kuada \& Sorensen, 2010) argue that a leader should be able to provide vision, shape values and listen to the voices of members of their teams in order to manage the team effectively.

Development of global leaders requires corporate to select the person possessing the appropriate characteristics of global leadership. The individual's personality cannot be taught, it can be improved, but not without individual effort. Hence, global leaders require the right 'state of mind' in order to become successful leaders. The program for global leadership development must include a focus on personal competencies. Personal competencies become the factor, which can determine the merit of training and experience. Global corporate can have the best global leadership development program using formal training, collaboration and international assignments but be unable to create successful global leaders. The success of training and experience is dependent on the leading candidate's personal competencies, whether he/she is motivated and willing to participate in intercultural training program or interactions. Hence,firms ignoring competencies required to fulfil job positions as well as existing personal competencies will do so at their own risk (Mendenhall \& Bird, 2013).

\section{Methodology}

Globalisation has affected national boundaries, influenced national cultures and provided new challenges for businesses. The need to interact with a multicultural environment provides new challenges not only for businesses but also corporate research. Global leadership is the phenomenon that is on the research agenda due to globalization. The understanding and use of this phenomenon are necessary to put words on the new challenges encountered.

Global leadership is widely used in corporate theory and like all other fields of inquiry, the corporate study is paradigmatically anchored (Gioia \& Pitre, 1990). The philosophical foundation within corporate studies has a focus on the creation of knowledge and how knowledge is interpreted differently across different paradigmatic presumptions (Gioia \& Pitre, 1990). In social sciences, the distinction between the degrees of knowledge creation has been characterized by the objective-subjective continuum (Kuada, 2012). The objective and subjective approach to research are two extremes towards understanding the social reality.

\section{Paradigmatic Foundation}

Following the objective-subjective debate, this research paper will pursue a subjective approach to research, with an ontological, epistemological and human nature that is clearly defined by individual ability to influence and developed their own reality. Hence, presuming that the social reality is subjective and therefore socially constructed.

Social constructivism is a paradigm, where a paradigm describes presumption about reality, e.g. it is characterized as a 'belief system' (Kuhn, 1977, as cited in Hazlett, McAdam \& Gallagher, 2005). Social constructivist researchers believe that where human beings are unable to control the laws of nature, they are however able to control and influence the social world both consciously and unconsciously (Wadel \& Wadel 2013). To determine whether the phenomena under investigation are part of the natural and social 
world, it is necessary to ask what actually is under investigation (Collin, 1998). Global leadership is a truly man-made phenomenon and an outcome of increased need for intercultural interaction and an understanding of multiple cultures. Hence, the phenomenon is developed and influenced by the social reality.

\section{Theory Building}

In the search for new knowledge, past experiences and training structures researchers' approach to the theory development (Andersen \& Kragh, 2009; Bendassolli, 2013). The aim of this research article is to build knowledge and search for the truth, where the truth can either be universal or situational. Theory building is a way for researchers to be able to build knowledge (Zikmund et al., 2013). A theory explains a phenomenon, by describing how things are related to the phenomenon in question (Zikmund et al., 2013). Global leadership is of such phenomenon. The theory is constructed based on the interpretation of data collection, where theory originates from the researcher's attempt to make sense of the observed facts (Timmermans \& Tavory, 2012).

The development of a theory is about the creation of an understanding and explanation of an observed reality, where constructs can provide a helping hand. The identification of constructs to aid the explanation of the phenomenon is based on the researcher's previous knowledge. The theoretical foundation within a field of research will improve the choice of appropriate constructs (Benadassolli, 2013). It is only through building a relationship between constructs that researchers can create an understanding between different constructs and how they affect the relevant phenomenon. Through developing propositions, e.g., statements explaining the linkage between concepts, a relationship between constructs describing the phenomenon is developed (Zikmund et al., 2013).

The goal of the theory is to understand and be able to predict outcomes (Zikmund et al., 2013). The constructs of global leadership aid the explanation of what it means being a global leader. An understanding of the phenomenon would not be possible if it were not for constructs such as cognitive complexity, savvy, emotional and cultural intelligence etc. The constructs will aid to understand how global leadership is developed.

\section{Data Collection}

To provide an understanding and explanation of global leadership previous literature $o$ the phenomenon will be used. Meaning that this article focuses on providing a theoretical contribution based on secondary data. Literature will provide an understanding of what constructs are used to explain global leadership and aid the article's discussion. To use secondary data solely is not optimal being led by socially constructivist presumptions. It will restrict the content validity of this article, as the propositions made will not be tested out through primary data collection. The attempt not to find empirical verification of theoretical findings breaks with the subjective aped. However, this is necessary in order to provide a theoretical link.

The concern using secondary data, as a primary resource for knowledge is the fit of the data obtained (Witheside, Mills \& McCalm, 2012). As the primary concern of this article will be on the theoretical understanding of the phenomenon, the primary data collection of the sources used will not be tested and used. The use of secondary data as a theoretical basis is to provide an understanding of how global leadership is defined, what constructs it constitutes of the how it proposed developed.

\section{Research Design}

This article will have a social constructivist approach towards understanding social reality. Let by the social constructive approach to social science, this article will aim at understanding global leadership as dependent on human interactions. The phenomenon is manmade and it is up to the individual and corporate to develop global leaders.

\section{CONCLUSION}

The speed of globalization and the advancement of communication technology have decreased physical boundaries. Global corporate are growing ever more complex, where strategy, staffing, management and leadership are concerns on the global scale and global markets is an unavoidable fact for corporate. As business markets are becoming increasingly interlinked, it becomes near impossible to not have a global perspective on business activities (Rosen \& Digh, 2001).

A direct outcome of globalization is the phenomenon global leadership which is the role that makes use of 
mindset in his/her leadership approach towards dealing with the diversity. Global leadership draws on personal competencies and cognitive complexity. The need for experience in order to develop global leadership is the required competencies are the crucial factor.

A global leader portraying a global mindset does not mean that he/she is free from his/her national identity. Earley and Mosakowski (2004) description of a chameleon, possessing a high level of cultural intelligence, is a very uncommon leadership type. Where such a leader could be mistaken for a native. A global leader with cultural fluency in today's global business world is practically impossible (Nardon \& Steers, 2008). The notion of a specific global leadership mindset as a requirement for successful global leaders becomes void. As global leadership, literature fails to define who a global leader is, a specific global leadership mindset cannot prevail. Global leaders need to adapt to different contexts, due to market difference and changing participants. Making global leaders need to adapt their leadership style depending on the context. Global leadership is also contextual. Speaking of global leaders, care should be taken, development and operation depend on the context that the individual and corporate operates in.

\section{REFERENCES}

1. Ahlstrom, D., and Bruton, G.D. (2010) "International Management - Strategy and Culture in the Emerging World" South-Western Cengage Learning.

2. Alon, I., and Higgins, J.M. (2005) "Global leadership success through emotional and cultural intelligence” Business Horizons, Vol. 48, pp.50112.

3. Andersen, P. and Kragh, H. (2009) "Sense and Sensibility: Two approaches for using existing theory in theory-building qualitative research" Industrial Marketing Management, Vol. 39, pp.4955.

4. Bendassolli, P.F. (2013) "Theory Building in Qualitative Research: Reconsidering the Problem of Induction" Forum Qualitative Sozialforschung/Forum: Qualitative Social Research, Vol. 14, No.1, Art. 25 URL: http://www.qualitative-

research.net/index.php/fqs/article/view/1851/3499 Found [19.04.14]
5. Bird, A., Mendenhall, M., Stevens, M.J, and Oddou, G. (2010) "Defining the content domain of intercultural competence for global leaders" Journal of Managerial Psychology, Vol.25, No.8, pp.810-28.

6. Bolden, R., Gosling, J., Marturano, A. and Dennison, P. (2003) "A review of leadership theory and competency framework" Center for Leadership Studies, University of Exeter, pp.1-44.

7. Bowen, D.E. and Inkpen, A.C. (2009) "Exploring the Role of "Global Mindset" in Leading Change in International Contexts" The Journal of Applied Behavioral Science, Vol. 45, No.2, pp.239-60.

8. Bucker, J. and Poutsma, E. (2009) "Global management competencies: a theoretical foundation" Journal of Managerial Psychology, Vol.25, No.8, pp.829-44.

9. Butler, C.L, Zander, L., Mockaitis, A., and Sutton, C. (2012) "The Global Leader as Boundary Spanner, Bridge Maker, and Blender" Industrial and Organizational Psychology, pp.240-43

10. Caligiuri, P. (2006) "Developing global leaders" Human Resource Management Review, Vol.16, pp.219-228.

11. Conner, J. (2000) "Developing the global leaders of tomorrow" Human Resource Management, Vol.39, Nos. 2 \& 3, pp.147-157.

12. Czinkota, M., Ronkainen, I., Moffett, M., Marinova, S., and Marinov, M. (2009) “International Business " John Wiley \& Sons, Ltd European Edition.

13. Earley, P.C. and Mosakowski, E. (2004) "Cultural Intelligence" Harvard Business Review, Vol.82, No.10, pp.139-46.

14. Etemad, H. (2004) "Internationalization of Small and Medium-sized Enterprises: A grounded Theoretical Framework and an Overview" Canadian Journal of Administrative Science, Vol.21, No.1, pp.1-21.

15. Gioia, D.A. and Pitre, E. (1990) "Multiparadigm Perspectives on Theory Building" Academy of Management Review, Vol.15, No.4, pp.584-602.

16. Gregersen, H.B., Morrison, A.J., and Black (1998) "Developing Leaders for the Global Frontier" Sloan Management Review, pp.21-32.

17. Hazlett, S., McAdam, R. and Gallagher, S. (2005) "Theory Building in Knowledge Management: In Search of Paradigms" Journal of Management Inquiry, Vol.14, No.1, pp.31-42.

18. Hocking, J.B., Brown, M. and Harzing, A.W. (2007) "Balancing global and local strategic contexts: Expatriate knowledge transfer, 
International Journal of Trend in Scientific Research and Development (IJTSRD) ISSN: 2456-6470

applications, and learning within a transnational organization" Human Resource Management, Vol.46, No.4, pp.513-33.

19. House, R., Javidan, M., Hanges, P. and Dorfman, P. (2002) "Understanding cultures and implicit leadership theories across the globe: an introduction to project GLOBE” Journal of World Business, Vol.37, pp.3-10.

20. Javidan, M. and House, R.J. (2001) "Cultural Acumen for the Global Manager: Lessons from Project GLOBE" Organizational Dynamics, Vol.29, No.4, pp.289-305.

21. Johnson, J. and Vahlne, J.E. (1977) "The internationalization process of the firm: A model of knowledge development and increasing foreign market commitment" Journal of International Business Studies, 8(1), pp.23-32.

22. Johnson, J. and Vahlne, J.E. (2009) “The Uppsala internationalization process model revisited: From liability of foreignness to liability of outsidership" Journal of International Business Studies, Vol. 40, pp.1411-31.

23. Jokinen, T. (2005) "Global leadership competencies: a review and discussion" Journal of European Industrial Training, Vol.29, No.3, pp.199-216.

24. Kets de Vries, M.F.R. and Treacy-Florent, E. (2002) "Global leadership from A to Z: Creating High Commitment Organizations” Organizational Dynamics, Vol. 30, No.4, pp.295-309.

25. Kiessling, T. and Harvey, M. (2005) "Strategic global human resource management research in the twenty-first century: an endorsement of the mixed-method research methodology" The International Journal of Human Resource Management, Vol.16, No. 1, pp.22-45.

26. Kotter, J.P. (1990) "What Leaders Really Do", Best of HBR, Reprinted 2001 by Harvard Business Scholl Publishing Corporation.

27. Kuada, J. (2010) "Creativity and Leadership in cross-cultural context: The role of expatriates", chapter 2, pp.9-23, in Kuada, J. and Sørensen, O.J. (Eds.) (2010) "Culture and Creativity in Organizations and Societies" Adonis \& Abbey, First edition.

28. Kuada, J. (2012) "Research Methodology - A project guide for university students" Samfunds literature, 1 st edition.

29. Kuada, J. and Sørensen, O.J. (2010) "Culture-inaction and creative learning in cross-border $R \& D$
Teams", chapter 3, pp.25-49, in Kuada, J. and Sørensen, O.J. (Eds.) (2010) "Culture and Creativity in Organizations and Societies" Adonis \& Abbey, First edition.

30. Kuhn, T. S. (1977) "Second thoughts on paradigms", in T. S. Kuhn (Ed.), "The essential tension" (pp. 293-319) Chicago: University of Chicago Press.

31. Leung, K., Bhagat, R.S., Buchan, Erez, M., and Gibson, C.B. (2005) "Culture and international business: recent advances and their implications for feature research" Journal of International Business Studies, Vol. 36, pp-357-78.

32. Mendenhall, M.E., and Bird, A. (2013) "In search of global leadership” Organizational Dynamics, Vol.42, Issue 2, pp.167-174.

33. Morrison, A.J. (2000) "Developing a Global Leadership Model" Human Resource Management, Vol.39, Nos. 2 \& 3, pp.117-131.

34. Nardon, L., and Steers, R.M. (2008) "The New Global Manager: Learning Cultures on the Fly'Organizational Dynamics, Vol.37, No. 1, pp.47-59.

35. Osland, J.S. (2008) "Overview of the global leadership literature”, in Mendenhall, M., Osland, J.S., Bird, A., Oddou, G. And Maznevski, M.L. (Eds): "Global Leadership: Research, Practice and Development", Routledge, London, pp.34-63.

36. Osland, J.S., and Bird, A. (2000) "Beyond sophisticated stereotyping: Cultural sensemaking in context" Academy of Management Executives, Vol.14, No.1, pp.65-79.

37. Osland, J.S., Bird, A., Mendenhall, M., and Osland, A. (2006) "Developing global leadership capabilities and global mindset: a review" in Stahl, G.K. and Björkman, I. (Eds): "Handbook of Research in International Human Resource Management" Edward Elgar Publishing Limited.

38. Rosen, R. and Digh, p. (2001) "Developing Globally Literate Leaders” $\mathrm{T}+\mathrm{D}$, Vol.55, No.5, pp. 70-81.

39. Sanchez-Runde, C., Nardon, L., and Steers, R.M. (2011) "Looking beyond Western leadership models: Implications for global managers" Organizational Dynamics Vol. 40, pp.207-13.

40. Soderberg, A.M. and Holden, N. (2002) "Rethinking Cross-Cultural Management in a Globalizing Business World" International Journal of Cross-Cultural Management, Vol.2,

41. No.1, pp.103-21.

42. Stroh, L.K., and Caligiuri, P.M. (1998) "Strategic human resources: a new source of competitive 
International Journal of Trend in Scientific Research and Development (IJTSRD) ISSN: 2456-6470

advantage in the global arena", The International Journal of Human Resouce Management, Vol.9, No.1, pp.1-17.

43. Sutton, C., Zander, L. And Stamm, K. (2013) "Global leadership and supportive stereotypes" European International Management, Vol. 7, No.5, pp. 604-622.

44. Suutari, V. (2002) "Global leader development: an emerging research agenda" Career Development International, Vol.7, No.4, pp.21833.

45. Terrell, S., and Rosenbusch, K. (2013) “Global Leadership Development: What Global Organizations can do to Reduce Leadership Risk, Increase Speed to Competence, and Build Global Leadership Muscle” People \& Strategy, Vol.36, Issue 1, pp. 40-6.
46. Timmermans, S. And Tavory, I. (2012) "Theory Construction in Qualitative Research: From grounded theory to abductive analysis" American Sociological Association, Vol.30, No.3, pp.167186.

47. Witheside, M., Mills, J. and McCalm, J. (2012) "Using Secondary Data for Grounded Theory Analysis” Australian Social Work, Vol.65, No.4, pp.504-516.

48. Yukl, G. (2010) "Leadership in Organizations" Pearson, 7th edition.

49. Zander, L., Settling, P. and Makela, K. (2013) "Leading global virtual teams to success" Organizational Dynamics, Vol. 42, pp.228-37.

50. Zikmund, W.G., Babin, B.J., Carr, J.C. and Griffin, M. (2013) "Business Research Methods" South-Western CENGAGE Learning, 9th Edition, International Edition. 